\title{
Filosofia Africana: um estudo sobre a conexão entre ética e estética
}

\author{
African Philosophy: a study on the connection between ethics and aesthetics
}

\author{
Naiara Paula*, Claudia Wer ${ }^{* *}$
}

\begin{abstract}
Resumo: O artigo articula a relação da ética com a estética Africana através de dois conceitos de base ancestral defendidos por expoentes do pensamento africano nos textos: "Complementaridade Binária" de Sophie Bosede Oluwole e "Kugusa Mtima" de Dona Marimba Richards. O texto analisa aspectos vitais da cosmovisão Africana que reverberam na produção ético-estética dos povos Africanos e destaca o papel primordial da vida espiritual para a experiência Africana, sobretudo, nos desafios contemporâneos, como forma de afirmação e construção de uma consciência nacional.
\end{abstract}

Palavras-chave: Ética africana; Estética Africana; Complementaridade binária, Kugusa Mtima, Cosmovisão Africana

\begin{abstract}
The article articulates the relationship between ethics and African aesthetics through two ancestral concepts defended by exponents of current African thought: "Binary Complementarity" by Sophie Bosede Olewole and "Kugusa Mtima" by Dona Marimba Richards. The text analyzes vital aspects of the African worldview that reverberate in the ethical-aesthetic production of the African people and highlights the primordial role of the spiritual life for the African experience in the contemporary challenges, as a form of affirmation and construction of a national consciousness.
\end{abstract}

Key words: African ethics; African aesthetics; Binary complementarity, Kugusa Mtima, African worldview

\section{Introdução}

O presente artigo discute os padrões Éticos que reverberam na Estética Africana a partir da análise de dois artigos: "A Estética Africana e a consciência nacional” de Dona Marimba Richards, um capítulo do livro “A Estética Africana” organizado por Kariamu Welsh-Asante, e "Complementaridade binária e a busca por uma nova ordem (social) mundial" do livro "Socrates and Orúnmilà" de Sophie Bosede Oluwole. O estudo destes autores deriva das investigações do projeto de pesquisa no Laboratório de Licenciatura e Pesquisa Sobre o Ensino de Filosofia (LLPEFIL), através do Núcleo de Filosofia Africana, no Instituto de Filosofia e Ciências Humanas (IFCH), da Universidade do Estado do Rio de

\footnotetext{
* Naiara Paula é escritora, editora, formada em Artes pela EAV-Parque Lage, bacharel e licenciada em Filosofia, mestra em Crítica e História da Arte, doutoranda em Filosofia CAPES-UERJ, professora orientadora de pesquisa LLPEFIL-UERJ e Lab. Geru Maa-UFRJ. E-mail:_naiarapaula.e@gmail.com ** Claudia Wer é atriz, graduada em Filosofia, especialista em Direitos Humanos, Gênero e sexualidade; Produtora Cultural e pesquisadora LLPEFIL-UERJ. E-mail:_claudia.wer1@gmail.com.
} 
Janeiro (UERJ), sob pesquisa e orientação de pesquisa da doutoranda em Filosofia e Pesquisadora Naiara Paula.

A relação entre a ética e a estética, na cosmovisão africana, faz pensar um conjunto de valores sobre os quais fazemos escolhas e decidimos comportamentos, também imbricados nas diversas produções estéticas. Podemos pensar, ainda, sobre a possibilidade do ideal estético influir nas demandas éticas, sob a perspectiva de um mundo em interconexão.

Ainda preservando distinções entre a forma de pensar ocidental e africana sobre ética e estética, é possível uma base de entendimento similar sobre ambas as vertentes. $\mathrm{O}$ objeto estético demanda uma certa harmonia, um certo modo de estar no mundo que projeta em nós uma plenitude. Existe uma identidade qualitativa peculiar ao estético, assim como na Ética existem peculiaridades prescritivas, que sinalizam para as pessoas e grupos como devem direcionar suas ações.

Cumpre percorrer uma breve contextualização sobre as obras dessas autoras, para melhor compreensão do que se trata a filosofia africana dentro da cosmovisão africana. Em seguida, aponto aspectos relevantes das reverberações da ética na concepção da estética africana e seu amalgama como a concepção de uma vida plena, como uma proposta de reconceitualização de "estética” com uma base espiritual, fiel ao utamaroho africano (vida espiritual) defendida por Dona Marimba Richards.

\section{Contextualizando a jornada}

Os povos africanos têm uma forma particular de viver e expressar o mundo que os caracterizam. Essa forma e cosmovisão de mundo embasa o constructo ético-filosófico africano e S. B. Oluwole tem sólido trabalho sobre Filosofia Africana e nesta obra coloca o Ifá e a tradição oral Yorubá em destaque e como ponto de partida para explicar a cosmovisão africana. Neste artigo, a autora apresenta características e novos fatos para uma comparação entre Sócrates e Òrúnmìlà, como dois grandes Mestres da tradição ocidental e Africana, respectivamente.

O Culto de Òrúnmilà-Ifá é originário da África Ocidental e, mais especificamente, da cultura Yorubá que concebe o mundo como formado por elementos físicos, humanos e espirituais. Os elementos físicos amplamente divididos em dois planos de existência: ayé (terra) e òrun (céu) ${ }^{1}$, que durante uma fase ancestral da mitologia compartilhavam um território comum.

Assim, para a compreensão da filosofia de Òrúnmilà-Ifá é fundamental a análise interpretativa da cosmovisão própria, com arcabouço complexo de divindades hierarquizadas a partir de um Ser Supremo: Òlódùmarè que lidera e organiza a estrutura e

${ }^{1}$ ABIMBOLA, A concepção iorubá da personalidade humana, p. 2. 
o movimento entre o céu e a terra, mobilizando no sentido do bem e da paz as demais arqui-divindades, ancestrais, fenômenos da natureza e orisá.

A ancestralidade é destaque nessa cultura. A figura do ancestral, uma pessoa ou entidade reverenciada por suas virtudes e ensinamentos éticos, geralmente, anciãos que repassam valores de geração a geração firmando uma forte característica de tradição oral com princípios voltados para a formação do bom caráter, da convivência harmoniosa e de respeito ao outro e a natureza.

No trabalho de Oluwole, contudo, é importante compreender que Òrúnmìlàe as outras figuras do Corpus Literário Ifá não são deuses no significado ocidental do termo, também não apenas figuras mitológicas, como são deuses no Monte Olimpo na tradição grega e sim, nesta pesquisa, a autora, nos leva a entender Òrúnmìlà como ser humano histórico, que foi reverenciado e "deificado" após sua morte, por causa de sua contribuição para a filosofia, ciência política e diversos conhecimentos que aprimoraram o conjunto de saberes do povo.

Tendo realizado extensa pesquisa sobre Òrúnmìlà, Oluwole apresenta características importantes de arcabouço filosófico deste Mestre e seus ensinamentos sobre a "vida plena" do indivíduo e sociedade e faz um paralelo com a produção socrática sobre a "vida boa".

Oluwole reconhece a contribuição Socrática para a construção do conhecimento ético com sua preocupação da constituição individual e social, mas enfatiza que esta visão não é exclusiva do conhecimento ocidental e ainda mais, mesmo a produção filosófica ocidental posterior não deu conta do vácuo conceitual que existe, por exemplo, na concepção atual de direitos humanos. Ainda após a fase iluminista, a cisão entre sujeito e objeto ("um ou outro") oblitera a formatação de direitos que possam ser estabelecidos como fundamentais e inalienáveis, daí a necessidade de estabelecimento de um outro arcabouço lógico, não excludente. Afirma a pensadora:

A demanda intelectual por um axioma científico em termos do qual os Direitos Humanos sejam justificados racionalmente, precisa ser satisfeita. A questão é que, enquanto a realidade é identificada e formulada dentro estruturas conceituais de oposições binárias, com um inerente "um ou outro", assumido no sentido exclusivo, em que toda e cada existência não é apenas independente da outra, mas em oposição a isto, não pode haver racionalmente interesse e obrigação inalienável por parte de um indivíduo de reconhecer e respeitar a existência e igualdade de direitos de outros seres humanos. ${ }^{2}$

A partir dessas reflexões iniciais, Oluwole revela seus argumentos contra um jogo de oposições que se constituem um verdadeiro paradoxo para a experiência humana, uma

${ }^{2}$ OLUWOLE, Socrates and Orunmila. Two Patron Saints of Classical Philosophy, p. 159. 
vez que todo fenômeno pareado (binário) existe independentemente do outro e, na visão Africana, complementarmente ao outro.

Assim, a filosofia africana pode contribuir para superar a oposição binária via a Complementaridade Binária, sua proposta trata-se de um conceito que reabilita uma visão de mundo sistêmica e integrada, capaz de fazer o ser humano se entender e se colocar sempre “em relação a”, como explica a pensadora: “... como pode a 'cara' e a 'coroa' de uma moeda existir independentemente uma da outra? Quão significativa é a ideia de uma montanha que não é complementada pela ideia de um vale? O lado frontal de uma medalha existe separadamente da parte de trás? O fato de que cada aspecto pareado dessa existência apareça como o oposto do outro, não justifica a crença de uma existência independente ou ainda, o funcionamento correlato de duas existências de oposição irreconciliável. A experiência humana é da existência pareada com aspectos complementares entre si”. ${ }^{3}$

Após reconhecer o que há de mais original africano se desvela na filosofia africana ancestral, a jornada deste texto continua com Dona Marimba Richards que estabelece em seu texto uma relação entre a espiritualidade com as necessidades políticas dos povos africanos, entendendo que as possibilidades dessa relação estão na natureza da estética africana.

Richards nos leva a refletir em qual medida a ética da "vida plena" ou ideal de vida estético "em interconexão" pode contemplar as demandas políticas para sedimentação de uma consciência nacional Africana, especialmente após a diáspora africana, assim diz a autora:

Uma consciência nacional é uma consciência política na qual os membros de um grupo se compreendem como compartilhando um destino comum, baseado em uma história cultural compartilhada e em uma origem radical. Uma consciência nacional Africana existe quando nos identificamos com a África como um ponto de origem simbólico, um princípio maternal ou criativo, que determina nosso ser coletivo ${ }^{4}$.

A proposta de Dona Marimba Richards é muito desafiadora, foca em como promover consciência nacional após o epistemicídio secular que negou e mesmo, bloqueou acesso inúmeros conhecimentos formadores de identidade do povo Africano, questão discutida por muito pesquisadores da diáspora Africana, como Ramose:

Os conquistadores da África durante as injustas guerras de colonização se arrogaram a autoridade de definir filosofia. Eles fizeram isto cometendo epistemicídio, ou seja, o assassinato das maneiras de conhecer e agir dos povos africanos conquistados [...] que não nivelou e nem eliminou totalmente as maneiras de conhecer e agir dos povos africanos

\footnotetext{
${ }^{3}$ Ibidem, p. 160.

${ }^{4}$ RICHARDS, The African Aesthetic and National Consciousness, p. 63.
} 
conquistados, mas introduziu, entretanto, e numa dimensão muito sustentada através de meios ilícitos e "justos", a tensão subsequente na relação entre as filosofias africana e ocidental na África ${ }^{5}$.

A base fundamental da resposta a esse desafio, segundo a autora, é a retomada do eixo estruturador e estruturante da civilização Yorubá, e aproximação ao princípio originário da ancestralidade Òrúnmilà-Ifá que leva as pessoas a formarem a consciência de si e que dirige a vida da comunidade, assim, um conjunto ético que repercute nas produções estéticas africanas. Ao longo de seu projeto, a autora introduz alguns termos africanos buscando "africanizar" a conceituação de forma crescente na perspectiva de afrocentricidade. ${ }^{6}$

Richards propõe uma reconceitualização de "estética" com base espiritual, para ser fiel ao utamaroho africano (vida espiritual). E afirma o Kugusa Mtima (tocar o coração) como um termo Africano de apoio ao entendimento e afirmação de africanidade. Trata-se da experiência africana de ser mobilizado e sensibilizado pelos fenômenos de forma autoconsciente, com tremenda capacidade de transformação da realidade.

\section{A concepção ética africana}

A extensa pesquisa de Oluwole sobre Socrates e Òrúnmìà mostra que existem semelhanças surpreendentes, ambos viveram em épocas próximas, cerca de 500 a. C. , também tiveram discípulos a quem transmitiram seus ensinamentos sobre virtudes como o ideal de vida plena (ou vida boa) e viviam em centros de vida intelectual e social de seus povos à época: Atenas na Grécia antiga e Ile-Ife, respectivamente. Tudo o que sabemos sobre eles advém de fontes secundárias, o que dá a esses dois Mestres um certo caráter lendário ou mesmo, mítico. Tais similaridades são detalhadamente explanadas na Introdução da obra. ${ }^{7}$

O mais inovador dessa comparação é, sem dúvida, a confrontação sobre as produções e ensinamentos desses Mestres, sinalizando um conjunto teórico, de visões e ideias muito similares, que a autora explicita em um quadro comparativo com as principais questões do pensamento desses patronos ${ }^{8}$.

Os achados de Oluwole evidenciam que Òrúnmìlà desenvolveu uma Filosofia dentro do Sistema Africano tradicional de pensamento de forma tão crítica e rigorosa quanto Sócrates, que inclui até mesmo, as bases de Álgebra e de Geometria. Deste modo, Oluwole

\footnotetext{
${ }^{5}$ RAMOSE, A Filosofia do Ubuntu e Ubuntu como uma Filosofia, p. 9.

${ }^{6}$ Conceito desenvolvido por Molefi K. Asante. Ver ASANTE, Afrocentricidade: A teoria da mudança social, 1980.

${ }^{7}$ OLUWOLE, Socrates and Orunmila. Two Patron Saints of Classical Philosophy, p. 21-30.

${ }^{8}$ Ibidem, p. 81-82.
} 
rebate a posição Ocidental que negam a existência de critérios, racionalidade e conteúdo crítico e científicos na Filosofia Africana e mesmo de alguns poucos estudiosos africanos como Kwasi Wiredu, Kwame Gyekye, Gerald Joseph Wanjohi, Peter O. Bodunrin, entre outros, que apontam um alto grau de abstração no corpus da produção do conhecimento tradicional africano.

Em suas conclusões, Oluwole esclarece como Sócrates, o Patrono da Filosofia ocidental clássica, faz distinções binárias na produção de sua Filosofia, criando um jogo de oposições que separa corpo e mente, imanente e transcendente e, porque não dizer, um mundo do lado de cá e outro do lado de lá - um mundo sensível e outro inteligível - ou seja, a realidade dividida em duas partes: o mundo sensível (mundo material), mediado pelas formas autônomas que encontramos na natureza, e que percebemos pelos sentidos; e o mundo das ideias (realidade inteligível) denominado de "mundo ideal”. Assim, aproxima-se da ideia de perfeição de algo aquilo que alcança a elevação do mundo das ideias, em que se observa já a aproximação com um ideal estético. Essa visão de mundos desarticulados em uma cisão vai impactar a produção filosófica de muitas gerações de filósofos no Ocidente por séculos posteriores.

Por outro lado, Òrúnmì̀̀, o patrono da filosofia africana clássica, tem como premissa uma cosmovisão abrangente e interconectada, que a autora passa a nomear como "Complementaridade binária”. Oluwole sinaliza este achado como uma grande contribuição da filosofia africana para a humanidade. Trata-se de um modo de pensar e visão de mundo sem cisão, ou ainda, de dois mundos em permanente relação. Superar a cisão proporciona perceber-se a si e o outro sem oposições. Também leva a perceber o outro como condição necessária para a minha própria existência como ser humano, em uma forma ancestral de fraternidade universal - mas com outro entendimento acerca do que seja universal - talhado naquilo que é comum a todos e que inclui todas as formas de vida e a própria Natureza.

A mesma concepção também pode ser encontrada no termo "Ubuntu" como termo fundamental da filosofia africana, amplamente estudado por Mogobe Ramose da Universidade da África do Sul, que desenvolveu Filosofia Africana através do Ubuntu.

Oluwole também faz referência a provérbios "bantu” redescobertos por Ramose por expressar o núcleo da filosofia do Ubuntu e do conceito de complementaridade binária,

\footnotetext{
${ }^{9}$ Ubuntu. Expressão Bantu. Consiste no prefixo "ubu" e a raiz "ntu". Evoca a ideia geral de ser-sendo. Ver RAMOSE, The ethics of ubuntu, p. 2. Este conceito ético enfatiza as alianças entre as pessoas e as relações entre estas. Trata-se de uma categoria epistêmica e ontológica fundamental do pensamento Africano dos grupos que falam línguas Bantu. Tal como o autor defende, Ubu-, como o mais amplo e generalizado ser sendo, está profundamente marcado pela incerteza, por estar ancorado na busca da compreensão do cosmos numa luta constante pela harmonia. Esta compreensão é importante, pois a política, a religião e o direito assentam e estão banhados da experiência e do conceito de harmonia cósmica. Ver RAMOSE. A Filosofia do Ubuntu e Ubuntu como uma Filosofia, 1999.
} 
evidenciando que as bases filosóficas africanas pressupõe um mundo em interconexão e não fragmentado ${ }^{10}$. Assim diz Ramose:

A lógica de Ubuntu é em direção ao sufixo formador de substantivos abstratos (dade). Esta lógica se coloca em oposição ao dogmatismo do raciocínio fragmentado. Um dos primeiros princípios da ética ubuntu é a libertação do dogmatismo. É flexibilidade orientada para o equilíbrio e para a harmonia no relacionamento entre seres humanos, e entre os últimos e o mais abrangente ser-sendo ou natureza. ${ }^{11}$

Transcrevo aqui alguns do provérbios "bantu" investigados por Ramose que Oluwole aponta como exemplo de metáforas socias, resultado inerente da Complementaridade Binária: ${ }^{12}$

1. Umuntu ugumuntu nga bantu

Ser um ser humano é afirmar a própria humanidade reconhecendo a humanidade dos Outros, e com base nisso, estabelecer relacionamento humano com eles ${ }^{13}$

2. $\quad$ Motho gase mphshe ga a tshewe sesotho

Nenhum ser humano pode ser tão inútil.

3. Kgosi ke kgoSi batho

A fonte e justificação do poder real é o povo.

4. Molato ga o bole

Justiça significa a restauração do equilíbrio perturbado.

5. $\quad$ Feta kgomo o tshware motho

Quando uma escolha deve ser feita entre preservar a vida e integridade de um ser humano ou construir riqueza, então o primeiro deve ser preferido e prevalecer.

Os achados e proposta de Oluwole sintonizam com a proposta de Marimba Richards para uma retomada do vínculo espiritual que favoreça a formação de uma consciência nacional, um vínculo que está acima de oposições binárias.

Dona Marimba Richards estabelece a relação entre a espiritualidade com as necessidades políticas dos povos africanos, uma relação de natureza da estética que se faz a base para a formação da consciência individual que se desdobra em consciência nacional e política, compartilhada.

A visão filosófica do Yorubá conserva o aspecto metafísico que reflete e aprofunda a sensibilidade para o sagrado. As vivências, experiências de vida e de mundo mantém a abertura espiritual na produção filosófica e reverbera no aprimoramento do

${ }^{10}$ Conceito desenvolvido por Oluwole como uma nova proposta de desenvolvimento via a cosmovisão Africana, recusando as premissas de uma visão de mundo binário, cindido e eurocentrado. Ver OLUWOLE, Socrates and Orunmila. Two Patron Saints of Classical Philosophy, p. 157 e 188.

${ }^{11}$ RAMOSE, A Filosofia do Ubuntu e Ubuntu como uma Filosofia, p. 4.

${ }^{12}$ OLUWOLE, Socrates and Orunmila. Two Patron Saints of Classical Philosophy, p. 161. (Tradução nossa).

${ }^{13}$ Ibidem, p. 42. 
autoconhecimento pessoal e na convivência ético-comunitária múltipla: relação do indivíduo consigo mesmo, com o outro e com a natureza. Um estado de completude que amalgama o aspecto humano e divino do indivíduo, de repercussões ético-estéticas, que foca no aprimoramento do indivíduo e suas relações e que, em algum grau impõe uma certa dificuldade de entendimento por parte de quem está mergulhado no modelo lógicofilosófico ocidental.

Entender que Òrúnmilà não faz uma ruptura entre o imanente e o transcendente, que se dão em uma espécie de continuidade, oportuniza que o indivíduo tome "conhecimento de si” "em relação a", apoia que o indivíduo seja consciente do seu pertencimento, através do processo de autoconhecimento contínuo, de autoavaliação, de discernimento e revisão dos seus valores.

Essa consciência de si mesmo está afinada com um tipo de vida filosófico pautado no bom caráter, no bem comunitário, na bondade e na convivência harmoniosa com todos os seres. Essa condição de existência possibilita o alcance da felicidade compartilhada, o encontro consigo mesmo e a plenitude de uma consciência voltada ao sagrado em um conjunto Ético-Estético amplificado, inclusivo e abrangente.

O sagrado reconsiderado como dentro do mundo, o lugar do mistério preservado. Diz Marimba Richards

Nesse sistema conceitual limitado [ocidental], "estética” é entendida como "conceito de beleza". Se pretende lidar com "gosto" e apreciação do "belo". A "Estética" lida com teorias do caráter essencial do "belo" e como ele pode ser julgado. A discussão europeia de "estética" torna-se analítica; o pathos (do grego - paixão) é intelectualizado; o mistério negado. O foco se torna o julgamento e a crítica ${ }^{14}$.

A visão africana, segundo Richards não trata o belo reduzido ao ajuizamento e nem a diretrizes específicas que determinem um tipo de gosto em oposição binária: "belo" ao "feio" que é irrelevante para as aspirações africanas. Nesse sentido, se coloca a proposta de reconceitualização estética fiel ao princípio espiritual africano. Diz a pensadora:

O universo é concebido como um todo espiritual no qual todo ser está interrelacionado. De fato, é a essência espiritual do universo que explica a interdependência dos seres dentro dele. É fenomenal. Está vivo.... Os mecanismos culturais estão se unindo, compartilhando e em coletividade. Essa visão do universo é ao mesmo tempo mística, espiritual e pragmática ${ }^{15}$.

\footnotetext{
${ }^{14}$ RICHARDS, The African Aesthetic and National Consciousness, p. 64.

${ }^{15}$ Ibidem.
} 
A abertura para o espiritual e a potente aderência para a cosmovisão Africana só pode ocorrer por uma mobilização que nos afete profundamente. Como fonte inspiradora para este chamado, Richards acentua e revigora um termo ancestral de origem Kiswahili"16 o "kugusa Mtima":

Kugusa Mtima é mais que um conceito analítico; é uma ideia sintetizadora. Unifica o processo criativo, o fenômeno da sensibilidade, a interação de energia, utamaroho ${ }^{17}$ e consciência. É politicamente prático, desde que possa ser usado para entender a natureza do "Ser Africano" e para os propósitos de reconstrução da realidade africana. Kugusa Mtima é uma espécie de energia magnética. Isso nos envolve em um campo de força. Isto é pulsação e vibração. Relaciona-se com o rearranjo e interação de partículas de energia em permutações e combinações de cor, forma bidimensional, som e forma tridimensional ${ }^{18}$.

$\mathrm{Na}$ perspectiva metafísica, Kugusa Mtima envolve as ideias de unidade, harmonia e espírito; um conjunto ético-estético, que ainda precisa assumido inteiramente em suas implicações psicológicas e políticas, para a transformação da realidade e favorecimento do povo africano.

\section{Considerações finais}

Para compreender a Filosofia de Òrúnmilà-Ifá e a sua importância para os afrodescendentes na diáspora é preciso resgatar as suas raízes em terras africanas, trajetória que este projeto estabeleceu a partir do estudo de textos de duas pensadoras importantes da Filosofia Africana, trazendo uma posição crítica sobre o que significa e a grande contribuição de África para o mundo.

Frente às demandas mundiais atuais, reconhecer essa contribuição é fundamental para a própria sobrevivência da Humanidade. O argumento de que o desenvolvimento de uma aldeia global viável é inevitável pode ser válido e até importante, mas como isso pode ser realidade em um mundo de tantas e tamanhas desigualdades? Um mundo no qual os benefícios, ou paradoxalmente, as violações dos chamados Direitos Humanos não atingem a todos os humanos da mesma forma? Como pontua Oluwole uma aldeia global viável não pode aceitar a suposição do individualismo nas Estruturas Conceituais de Oposição Binária, que também justifica o Capitalismo implacável como a única teoria racional econômica e política democrática da administração do Estado. ${ }^{19}$

\footnotetext{
${ }^{16}$ Língua Bantu.

${ }^{17}$ Vida Espiritual - força vital cultural. Tradução nossa para African utamaroho (spirit-life). Ver RICHARDS, The African Aesthetic and National Consciousness, p. 64.

${ }^{18}$ RICHARDS, The African Aesthetic and National Consciousness, p. 74.

${ }^{19}$ OLUWOLE, Socrates and Orunmila. Two Patron Saints of Classical Philosophy, p. 188.
} 
Neste mundo cindido, que produções ético-estéticas tem espaço? Estudar África e derivações afrodiaspóricas é interpretar, compreender e sentir uma certa sociedade, no tempo e no espaço, em sua plenitude e em sua complexidade histórica, que fazem com que essa produção de vida espiritual persista e resista. A filosofia de Òrúnmìlá-Ifá possui em todo o seu corpo filosófico-literário ensinamentos que englobam teologia, a metafísica, a ontologia, a matemática, a lógica, a geometria e demais ciências. A oralidade e o respeito a ancestralidade têm no todo desta filosofia lugar de destaque, pois o ensinamento oral é a palavra vivificada, favorece a troca, o convívio social e comunitário, com base em um viver ético-estético.

A história cultural europeia revela um processo contínuo e implacável de criação e reforço de uma consciência nacional que se dobra para uma débil perspectiva de universalidade que mantém um senso de destino comum que não reverbera para a maior parte da população do planeta.

O Desenvolvimento baseado na visão de mundo africana da complementaridade binária é o que a maioria dos estudiosos agora vê como a solução para as várias formas de convulsões sociais e do pensamento em todo o mundo ${ }^{20}$.

Oluwole nos mostra que existe um conhecimento pleno da precisão filosófica e científica. O sistema de pensamento Yorubá, um dos primeiros povos do planeta que formulou, desenvolveu e adotou um exercício de vida com base na complementaridade binária, em que todos os conhecimentos se ligam a um conhecimento maior, ancestral e espiritual e mobilizador de uma comunidade para o bem comum.

Diferentemente da filosofia ocidental derivada do racionalismo iluminista, a filosofia Yorubá e o Ubuntu não coloca o indivíduo no centro de uma concepção de ser humano. Este é todo o sentido do Ubuntu e do humanismo africano. Nessa filosofia o ser humano de fato humano, só se dá na relação com o outro, não há individualidade isolada. Este é um compromisso ético-estético com o outro seja quem for o outro, ou seja, profundo compromisso com a vida da cosmovisão Africana.

\section{Referências}

ABIMBOLA, Wande. A concepção iorubá da personalidade humana. Paris: Centre National de la Recherche Scientifique, 1981. Tradução disponível em: https://filosofiaafricana.weebly.com/uploads/1/3/2/1/13213792/wande abimbola__a_concep $\% \mathrm{C} 3 \% \mathrm{~A} 7 \% \mathrm{C} 3 \% \mathrm{~A} 30 \_$iorub\%C3\%A1_da_personalidade_humana.pdf

\footnotetext{
${ }^{20}$ Ibidem, p. 175.
} 
RAMOSE, Mogobe B. A Filosofia do Ubuntu e Ubuntu como uma Filosofia. In: RAMOSE. African Philosophy through Ubuntu. Harare: Mond Books, 1999. Tradução para uso didático por Arnaldo Vasconcellos. Disponível em: https:/filosofiaafricana.weebly.com/uploads/1/3/2/1/13213792/texto16.pdf

RAMOSE, Mogobe B. The ethics of ubuntu. In: COETZEE, Peter H.; ROUX, Abraham P.J. (eds). The African Philosophy Reader. New York: Routledge, 2002. Tradução para uso didático de Éder Carvalho Wen. Disponível em: https://filosofiaafricana.weebly.com/uploads/1/3/2/1/13213792/mogobe_b._ramose_-

_a \%C3\%A9tica do ubuntu.pdf

OLUWOLE, Sophie Bosede. Socrates and Orunmila. Two Patron Saints of Classical Philosophy. Lagos: Ark Publishers, 2014.

RICHARDS, Dona Marimba. The African Aesthetic and National Consciousness. In: WELSH-ASANTE, Kariamu (ed.). The African aesthetic: keeper of the traditions. London: Praeger, 1994. 